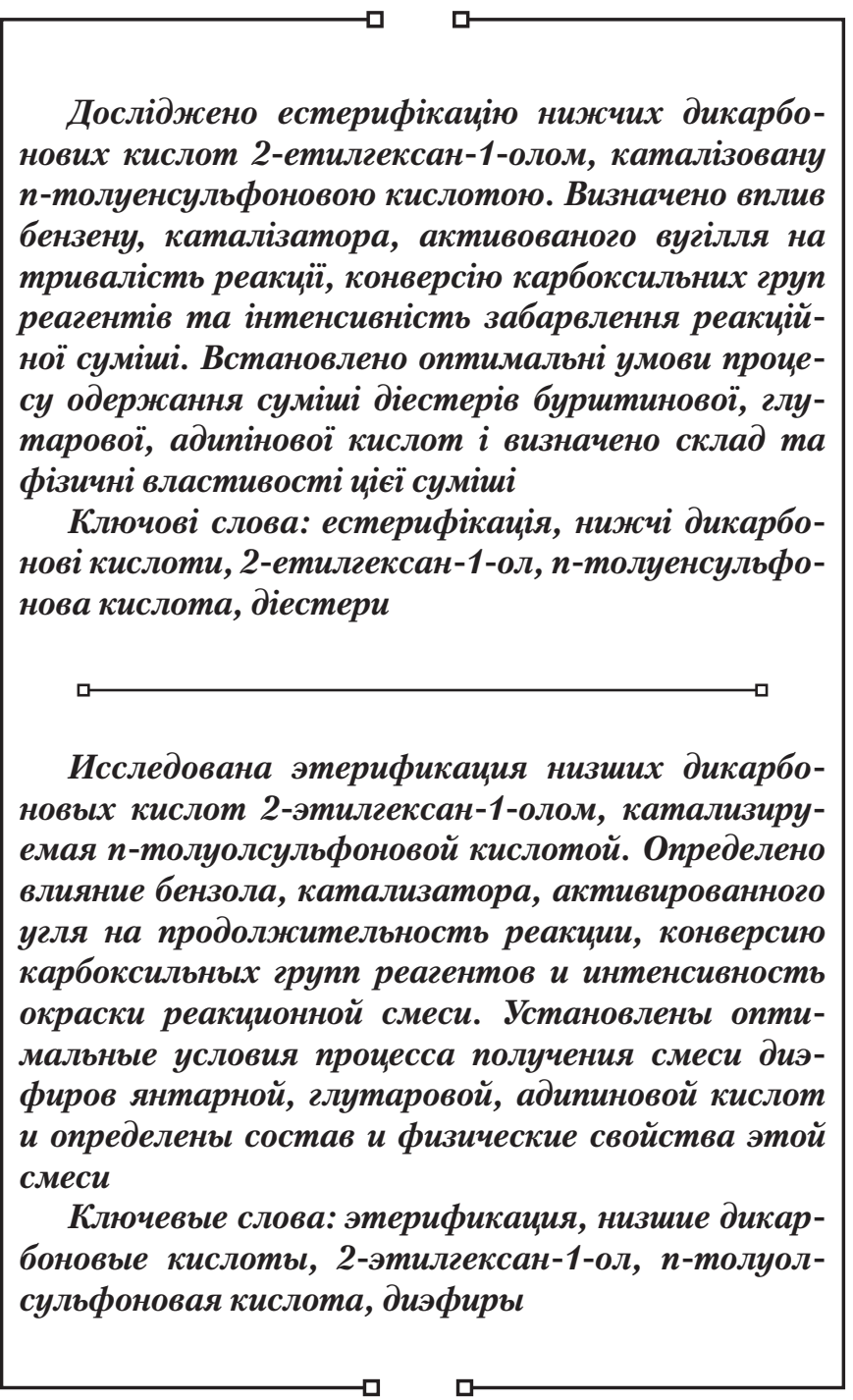

UDC 66.095.132

DOI: $10.15587 / 1729-4061.2017 .114324$

\section{RESEARCH INTO ESTERIFICATION OF MIXTURE OF LOWER DICARBOXYLIC ACIDS BY 2-ETHYLHEXAN-1-OL IN THE PRESENCE OF $p$-TOLUENSULFONIC ACID}

\author{
S. Me In y k \\ Doctor of Technical Sciences, Associate Professor* \\ E-mail: stepan.r.melnyk@Ipnu.ua \\ Y u. Me I n y k \\ $\mathrm{PhD}$, Associate Professor* \\ E-mail: yurii.r.melnyk@|pnu.ua \\ I. N y k u I y s h y n
} Doctor of Technical Sciences, Associate Professor* E-mail: nk_iren@ukr.net

L. S h e v c hu k

Doctor of Technical Sciences, Associate Professor*

E-mail: shev.lili2206@gmail.com

*Department of Technology of Organic Products Lviv Polytechnic National University S. Bandery str., 12, Lviv, Ukraine, 79013

\section{Introduction}

Products of esterification of aliphatic dicarboxylic acids are used as high-boiling solvents, lubricants, plasticizers of polymeric materials, etc. Constant extension of assortment of diesters by the synthesis of new individual compounds or obtaining of mixtures of diesters require setting optimal conditions for each particular process. Specifically, promising raw materials for obtaining diesteric plasticizers include by-products of production of adipic acid - so-called lower dicarboxylic acids (LDA). This is a mixture of succinic, glutaric and adipic acid, which after clearing from a catalyst of cyclohexanol oxidation can be exposed to esterification with obtaining relevant reaction products. Establishing of conditions that provide the maximal yield of diesters of LDA and 2-ethylhexan-1-ol, and determining the properties of the obtained substances will make it possible to solve the problem of obtaining and subsequent application of another valuable chemical product.

Accordingly, it is relevant to determine the influence of different factors on the esterification reaction, which determine maximum conversion of dicarboxylic acids as the most expensive reagent. The choice of a catalyst, which should be both affordable and highly reactive, is also important. Separation of reaction products and determining their phys- ical-chemical properties are important in terms of practical use of the obtained diesters.

\section{Literature review and problem statement}

Today, a whole range of esters of methanol and a mixture of succinic, glutaric and adipic acids - a by-product of manufacturing adipic acid - are produced.

We know about industrial production of the whole range of esters of methanol and mixtures of succinic, glutaric and adipic acids, which is a by-product of obtaining adipic acid [1]. These products are characterized by relatively high boiling and flash points, solubility, resistance, and low viscosity and toxicity.

That is why these esters are used as:

- solvents:

- plasticizers;

- raw materials for obtaining long-chain water-soluble polyamides that with epichlorohydrin form water-resistant resins for impregnation of paper;

- substances for washing off paints;

- intermediate polymer links, etc. [1].

We know about the use of wastes of chemical production for obtaining diester plasticizers. Specifically, water-acid 
and alkaline effluents, produced at the stage of cyclohexane oxidation, are used as raw materials. Then plasticizers, as well as light ester fraction and solutions of salts, are separated from the reaction mixture [2].

Wastes of production of butyl alcohols (ester distillate and bottoms of rectification of alcohols) and dietary ethanol (fusel oil, ester-aldehyde fraction) are also promising raw material for synthesis of diesters [3, 4].

One of the industrial plasticizers that are used for plasticizing PVC, polyvinyl acetals, esters of cellulose, polystyrene, acrylic and other synthetic resins is dioctyladipinate (DOA). It is a highly effective diester plasticizer, which provides compositions with cold-, wear- and light resistance, contributes to low viscosity and high viscous stability of plastisols [5].

Compared with esters of phthalic and phosphate acids, diesters of glutaric and succinic acids easily decompose biologically, do not show carcinogenic properties, are less toxic and do not deplete the ozone layer [6].

The use of waste and by-products of a number of productions as raw materials for obtaining diesters will not only provide the market with new chemical products. Lower cost of carbonic acids or alcohols, which are contained in by-products or wastes, will also allow decreasing the cost of diesters.

At the same time, information about getting diesters of mixture of LDA and 2-ethylhexan-1-ol, which according to its properties correlates with DOA was not found in literary sources.

One of the most important factors that determines conditions of the process and provides for high intensity of the process of obtaining diesters of dicarboxylic acids and alcohols, is a catalyst for the esterification reaction [7].

$p$-Toluensulfonic acid ( $p$ TSA) can be used in the form of an insoluble catalyst for transformations of various organic functional groups. In particular, $p$ TSA is used for transformation of ketoximes into corresponding amides, synthesis of $\beta$-indolyl ketones, indolo-[3,2- $\alpha]$-carbasols, $\alpha$-tosilation of ketones, etc. [8].

This catalyst also found widespread use in the esterification processes.

In particular, $p$ TSA efficiently catalyzes esterification of secondary alcohols and acids with formation of stable esters in the absence of a solvent in the presence of formed reaction water [9].

While using $p$ TSA as a catalyst of esterification of phthalic anhydride, the yield of dibutylphtalate exceeds $96 \%$ at the mole ratio of phthalic anhydride: butane-1-ol of 1:2.2. To achieve this yield, the amount of the catalyst should be $0.3 \mathrm{~mol} \%$ compared with the number of phthalic anhydride, the reaction time is 3 hours, and the temperature is $418-423 \mathrm{~K}$ [10].

In the presence of catalytic amount of $0.5 \mathrm{~mol} \%$ of $p$ TSA, both aromatic and aliphatic alcohols efficiently react with carbonic acids with moderate and high yields of esters (from 55 to $92 \%$ ). Maximal yield of esters is observed for alcohols containing electron donor groups [12].

High yield of methyl caffeinates $(84.0 \%)$ in reaction of esterification of caffeic acid by methanol, catalyzed by $p$ TSA, is achieved at molar ratio of methanol: acid of 20:1, temperature of reaction of $338 \mathrm{~K}$, ratio of mass of a catalyst to substrate of $8 \%$ and reaction time of 4 hours [12].

Through esterification of adipic acid by aliphatic alcohol $\mathrm{C}_{4}-\mathrm{C}_{5}$ and cyclohexanol in the presence of $p$ TSA, one obtains a mixture of diesters with a maximum yield of isobutyl- and butylcyclohexyl adipinate of 50.6 and $47.6 \%$ and isoamyl- and amyl cyclohexyl adipinate of 51.7 and $59.8 \%$, respectively. The catalyst provides conversion of dicarboxylic acid of more than $96.8 \%$ [13].

Combination of catalysis by $p$ TSA of esterification reaction of non-saturated aliphatic acid $\mathrm{C}_{9}-\mathrm{C}_{18}$ by ethanol and the action of ultrasound for $20 \mathrm{~min}$ at temperature of $298 \mathrm{~K}$ allows provision of esters' yield of 73-98\% depending on the structure of an acid [14].

For $p$ TSA, there are no disadvantages, characteristic for traditional catalysts of esterification - mineral acids. In particular, in the presence of $p$ TSA, dehydration of alcohols to olefins and resinification of organic compounds do not occur. However, $p$ TSA often contains a significant amount of impurities that can contaminate esterification products, so it is advisable to use it combined with activated carbon [15].

Specifically, paper [16] shows that the use of activated carbon of OU-A brand allows decreasing chromaticity of LDA esterification reaction products by the mixture of isoalcohols $\mathrm{C}_{4}-\mathrm{C}_{5}$ of fusel oil under conditions of $p$ TSA catalysis from 5.9 to $1.1 \mathrm{mg}$ of $\mathrm{I}_{2} / 100 \mathrm{~cm}^{3}$ of the reaction mixture.

Thus, modern trends of industrial organic chemistry are aimed at expanding raw material resources. This will make it possible to increase the range and decrease the cost of chemical products, including diesters of dicarboxylic acids. The application of such an active catalyst as $p$ TSA must also provide for efficiency of the esterification process.

That is why establishing regularities of reaction of LDA esterification by 2-ethylhexane-1-ol in the presence of $p$ TSA and determining of optimal conditions for the process is both of theoretical and of practical interest.

\section{The aim and objectives of the study}

The aim of present research was to establish the regularities of LDA esterification by 2-ethylhexan-1-ol in the presence of $p$ TSA as a catalyst under different conditions of the process and to identify and determine the properties of the obtained mixture of diesters.

To accomplish the set goal, the following tasks had to be solved:

- to determine the influence of benzene, the type and concentration of a catalyst, the type and amount of activated carbon on reaction duration, conversion (C) of carboxylic groups (CG) of reagents and chromaticity intensity of the reaction mixture;

- to establish the optimum conditions of the process of obtaining the mixture of diesters of succinic, glutaric and adipic acids and of 2-ethylhexan-1-ol;

- to determine the composition of the selected mixture of diesters and its physical properties.

\section{Materials and methods of research into esterification of lower dicarboxylic acids by 2-ethylhexan-1-ol}

\section{1. Materials and equipment used in the experiment}

We used as reagents in the esterification reaction:

- the mixture of LDA - by-products of production of adipic acid, purified, of brand A, TU U 24.1-05607824045:2007 of the following composition (\% by weight): succinic -29.2 , glutaric -37.8 , adipic -33.0 . The average molar mass of this mixture was $132.5 \mathrm{~g} / \mathrm{mol}$;

- 2-ethylhexan-1-ol (EH) of the highest grade, GOST (State standard) 26624-85. 
To enhance removal of water, which was formed during the esterification reaction, benzene of brand reagent grade, GOST (State standard) 5955-75 was added to reagents.

The following acids were used as catalysts:

$-p$-toluensulfonic ( $p$ TSA) - monohydrate of brand pure, TU 6-09-3668-77;

- sulfuric - concentrated, brand reagent grade, GOST 4204-77.

Activated carbon (AC) of brands BAU (GOST (State Standard) 6217-74), 208CP and DSL 220 (Chemviron Carbon, Belgium) were used for clarification of reaction products [17].

For analysis of reaction products, we used gas-liquid chromatograph "Tsvet-100" (USSR), photoelectrocolorimeter KFK-2 (Soviet Union), viscometer VPG-2 (Russian Federation), areometer AN (Ukraine).

\section{2. Methodology of the experiment and analysis of} the reaction mixture and mixture of diesters

The reaction of esterification of LDA by 2-ethylhexan-1-ol was conducted under non-stationary conditions of removal of water, which was formed during the reaction. Water was removed in the form of an azeotrope either with EH or with benzene. The reagents and the catalyst were loaded in a round-bottom flask, connected with the DeanStark trap, a reverse fridge, a thermometer and put on the bath of silicone oil, heated to temperature of $433 \mathrm{~K}$. The beginning of the reaction was determined after reaching the temperature of $373 \mathrm{~K}$. The process was going on at intense stirring of the mixture both by a magnetic stirrer and due to boiling. The reaction was carried out till complete cessation of accumulation of the water layer in the Dean-Stark trap. In the course of the reaction, the samples of the reaction mixture were taken in order to determine the acid number.

After completion of the reaction, where more than $99 \%$ CG conversion was achieved, the products of the experiments were neutralized with $2 \%$ solution of soda, washed with distilled water to neutral $\mathrm{pH}$ value; benzene and $\mathrm{EH}$ that did not react were removed from them by steam. The organic layer and the obtained mixture of diesters were separated from the water layer by decanting in a graduated funnel, respectively.

Acid number (AN) of the reaction mixture and the mixture of diesters, selected from it, was determined in accordance with the procedure [18]. Relative error of the analysis did not exceed $\pm 2.5 \%$.

Conversion of carboxylic groups of LDA mixture was calculated by the initial AN of the reaction mixture and the $\mathrm{AN}$ of the reaction products.

Chromaticity intensity of the reaction mixture and of separated diesters was determined by photoelectrocolorimete KFK-2 in the 20-mm long cuvette at the light wavelength of $440 \mathrm{~nm}$. Chromaticity of the solution was expressed by the iodine scale in $\mathrm{mg}$ of $\mathrm{I}_{2} / 100 \mathrm{~cm}^{3}$ of the substance.

The composition of the mixture of diesters was determined by the gas-liquid chromatograph "Tsvet-100" with the thermal conductivity detector. The length of the column was $1 \mathrm{~m}$, its diameter was $3 \mathrm{~mm}$, the fixed phase was $5 \%$ of Silicone SE30 on Chromaton N-AW. Consumption of gas-carrier of helium was $3 \mathrm{dm}^{3} / \mathrm{h}$, the volume of the analyzed sample was $2 \mu \mathrm{L}$. The current strength on the detector was $120 \mu \mathrm{A}$, the temperature of the evaporator was $523 \mathrm{~K}$, of the detector $-503 \mathrm{~K}$, of the column $-453 \mathrm{~K}$.
Viscosity of the mixture of LDA diesters and 2-ethylhexan-1-ol, separated from the reaction products, was determined by the viscometer VPG-2 by the time of flowing through the capillary (accuracy $\pm 2.0 \%$ ), relative density was determined by the areometer AN (accuracy \pm 0.0005 ). All measurements were performed under condition of 10-15-minute thermostating of the mixture of diesters.

\section{Results of research into esterification of} lower dicarboxylic acids by 2-ethylhexan-1-ol

We studied the influence of benzene, the type and concentration of a catalyst, the ratio of reagents, the type and the amount of activated carbon on the reaction duration, conversion of carboxylic groups of reagents, chromaticity of the reaction mixture.

It is known that aliphatic alcohols and water can form heterogeneous azeotropic mixtures, the boiling point of which is lower than that of alcohol and water. In particular, for 2-ethylhexan-1-ol it amounts to $372.25 \mathrm{~K}$, and water content in the mixture is $80 \%$ by weight [19]. Accordingly, in the esterification process, water is removed from the reaction mixture and is exfoliated from alcohol in the DeanStark trap. Performing the process of LDA esterification by 2-ethylhexan-1-ol in the presence of $p$ TSA showed that at mole ratio EH: LDA of 2.65:1 and concentration of $p \mathrm{TSA}$ of $1.3 \cdot 10^{-2} \mathrm{~mol} / \mathrm{dm}^{3}$, CG conversion of over $98 \%$ is achieved within 60 minutes of the reaction (Fig. 1, curve 1).

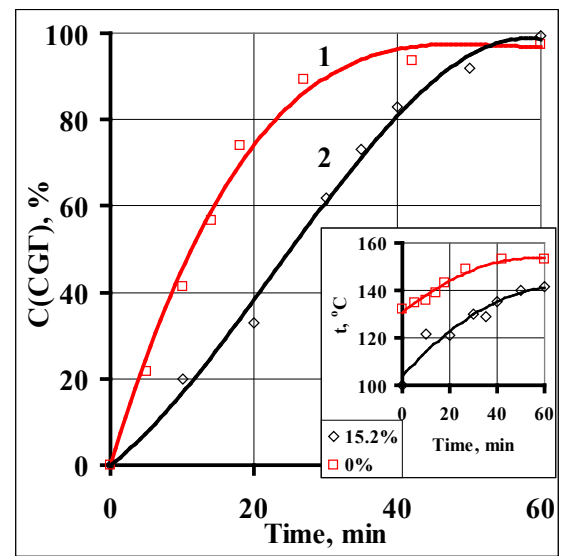

Fig. 1. Dependence of conversion of carboxylic groups of LDA on time in the process of esterification by 2-ethylhexan-1-ol:

1 - in the presence of $15.2 \%$ by weight of benzene;

2 - in its absence. Ratio of EH: LDA is 2.65:1 (mol). $\mathrm{C}(p \mathrm{TSA})$ is $1.3 \cdot 10^{-2} \mathrm{~mol} / \mathrm{dm}^{3}$

When adding $15.2 \%$ by weight of benzene, capable of forming with water a similar azeotropic mixture, the reaction of esterification at the initial stage flows more slowly as a result of temperature that is lower by $20-30 \mathrm{~K}$ (Fig. 1). However, it is obvious that water removal from the reaction mixture and equilibrium shift toward formation of diesters in the presence of benzene flows more effectively. Within the same time (60 min), conversion of CG reaches almost $100 \%$ (Fig. 1, Curve 2).

Comparison of effectiveness of catalysis of esterification of the mixture of lower dicarboxylic acids by $p$ TSA and sulfuric acid indicates that in the presence of the mineral acid, 
reaction flows at a lower rate. Even if the concentration of sulfuric acid is twice as high, the time, required to achieve CG conversion of more than $99 \%$, is $180 \mathrm{~min}$, which is three times as much as under the conditions of catalytic reaction of $p$ TSA (Fig. 2).

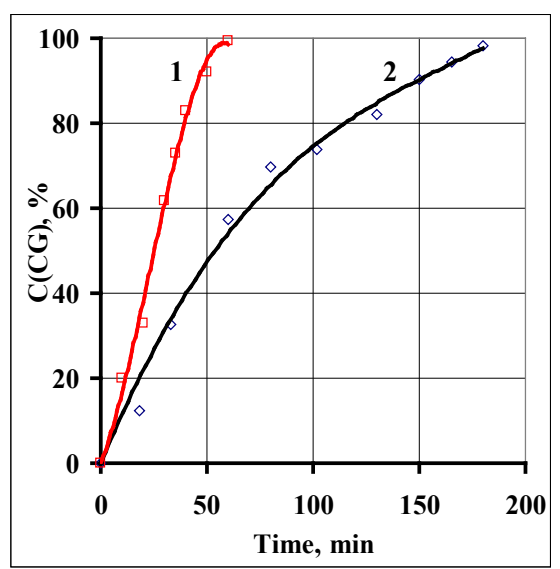

Fig. 2. Dependence of conversion of carboxylic groups of LDA on time in the process of esterification by 2-ethylhexan-1-ol in presence of: $1-1.3 \cdot 10^{-2} \mathrm{~mol} / \mathrm{dm}^{3} \mathrm{pTSA}$; $2-2.6 \cdot 10^{-2} \mathrm{~mol} / \mathrm{dm}^{3} \mathrm{H}_{2} \mathrm{SO}_{4}$. Ratio of $\mathrm{EH}$ :

LDA is $2.65: 1$ (mol). $\omega\left(\mathrm{C}_{6} \mathrm{H}_{6}\right)$ is $15.2 \%$ by weight

It was found that an increase in concentration of $p$ TSA from $7.2 \cdot 10^{-3}$ to $1.3 \cdot 10^{-2} \mathrm{~mol} / \mathrm{dm}^{3}$ has a significant impact on the change of $\mathrm{CG}$ conversion at the initial reaction stage, but at higher values of LDA conversion degree, this impact decreases (Fig. 3). In particular, for 180 minutes of the reaction, the difference between values of $\mathrm{C}(\mathrm{CG})$ is only $\sim 3 \%$.

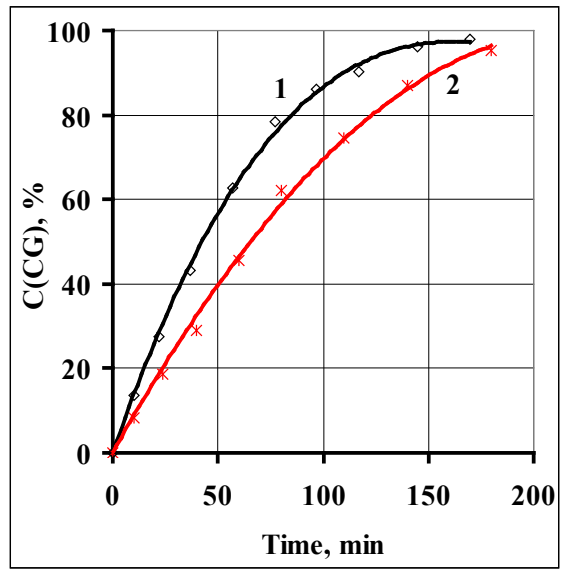

Fig. 3. Dependence of conversion of carboxylic LDA groups on time in the process of esterification by 2-ethylhexan-1-ol on concentration of $p$ TSA: $1-7.2 \cdot 10^{-3} \mathrm{~mol} / \mathrm{dm}^{3} ; 2-1.3 \cdot 10^{-3}$. Ratio of EH: LDA is $2.65: 1$ (mol). $\omega\left(\mathrm{C}_{6} \mathrm{H}_{6}\right)$ is $15.2 \%$ by weight

The use of different brands of activated carbon in the process of LDA esterification by 2-ethylhexan-1-ol in the presence of $p \mathrm{TSA}$ also affects the change of $\mathrm{CG}$ conversion over time (Fig. 4).

Activated carbon $208 \mathrm{CP}$ and DCL 200 is finely-dispersed; it is characterized by specific surface area of $1150-1250 \mathrm{~m}^{2} / \mathrm{g}$ [20]. Activated carbon BAU-A has dimensions of particles of $1-3.6 \mathrm{~mm}$ and specific surface area
(700-800 $\mathrm{m}^{2} / \mathrm{g}$ ) [21]. It is possible to assume that smaller particles' dimensions and larger specific surface of coal 208 CP and DCL 200 contribute to more intensive boiling and water removal from the reaction mass. As a result, there is higher intensity of reaction of LDA esterification by 2-ethylhexan-1-ol in the presence of carbon 208 CP and DCL 200, CG conversion within the first 10 minutes of reaction reaches 30-35\% (Fig. 4). In the absence of activated carbon and in the presence of $0.3 \%$ by weight of BAU-A, CG conversion is only $10 \%$ within 10 minutes of reaction.

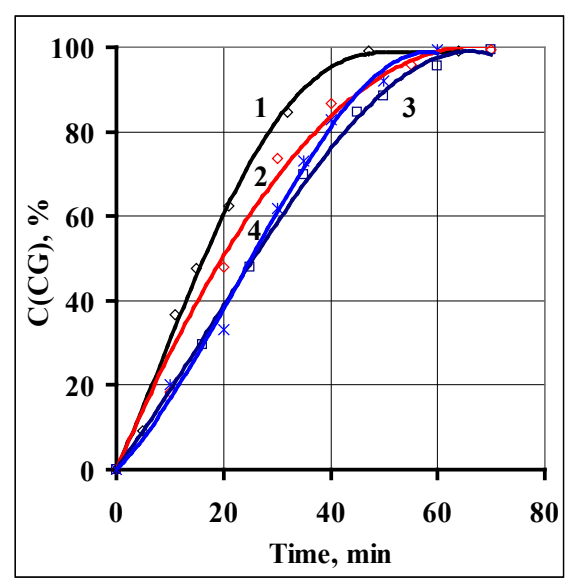

Fig. 4. Dependence of conversion of carboxylic groups of LDA on time in the process of esterification by 2-ethylhexan-1-ol in the presence of activated carbon: $1-208$ CP; 2 - DCL 200; 3 - BAU-A; 4 - carbon-free. $\omega(\mathrm{AC})$ is $0.3 \%$ by weight.

Ratio of EH: LDA is 2.65:1 (mol). $\omega\left(\mathrm{C}_{6} \mathrm{H}_{6}\right)$ is $15.2 \%$ by weight

An increase in content of activated carbon DCL 200 in the reaction mixture from $0.3 \%$ to $0.6 \%$ by weight, on the contrary, contributes to a sharp decrease in the process intensity (Fig. 5). Duration of LDA esterification by 2-ethylhexan-1-ol increases respectively by 3 times. This effect can be explained by the fact that $\mathrm{pH}$ value of carbon DCL 200 is 6-9. Alkaline components of activated carbon obviously neutralize a part of the catalyst, which decreases its active concentration and inhibits the reaction.

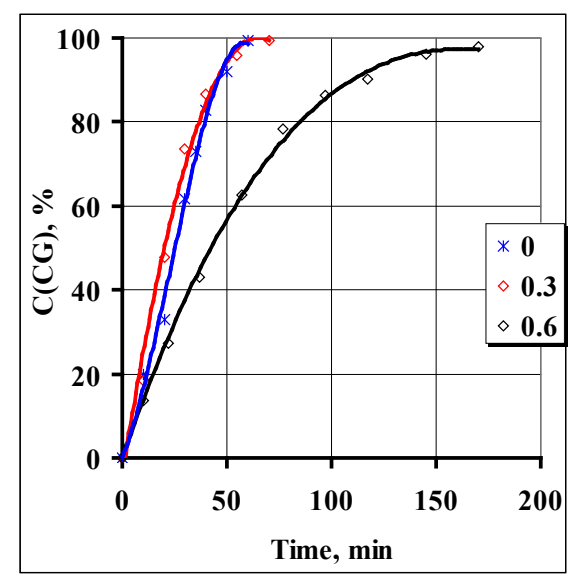

Fig. 5. Dependence of conversion of carboxylic groups of LDA on time in the process of esterification by 2-ethylhexan-1-ol on mass content of activated carbon DCL 200 in the reaction mixture. Ratio of EH: LDA is 2.65:1 (mol). C ( $p$ TSA) is

$1.3 \cdot 10^{-2} \mathrm{~mol} / \mathrm{dm}^{3} . \omega\left(\mathrm{C}_{6} \mathrm{H}_{6}\right)$ is $15.2 \%$ by weight 
The mixture of diesters was separated from the reaction mixture of products of LDA esterification by 2-ethylhexan-1-ol according to the technique, described in section 4.2. Determined chromatographic composition showed the following content of individual substances (in \% by weight): di-2-ethylhexylsuccinate is 31.3 , di-2-ethylhexylglutarate is 37.8 , di-2-ethylhexyladipinate is 30.9 . AN of the mixture was $0.1 \mathrm{mg} \mathrm{KOH} / \mathrm{g}$.

It was determined that density of the mixture of LDA diesters changes from $928 \mathrm{~kg} / \mathrm{m}^{3}$ (at $292.7 \mathrm{~K}$ ) to $876 \mathrm{~kg} / \mathrm{m}^{3}$ (at $372 \mathrm{~K}$ ). This change is described by the linear equation with correlation factor $\mathrm{r}^{2}=0.999$ :

$$
\rho=1122.1-0.6671 T, \mathrm{~kg} / \mathrm{m}^{3},
$$

where $T$ is the temperature of the mixture of diesters, $\mathrm{K}$.

Kinematic viscosity of the mixture of LDA diesters changes as temperature increases non linearly from $13.8 \mathrm{~mm}^{2} / \mathrm{s}$ $(292.7 \mathrm{~K})$ to $2.8 \mathrm{~mm}^{2} / \mathrm{s}(372 \mathrm{~K})$. The equation that describes this change $\left(\mathrm{r}^{2}=0.999\right)$ was derived by the least squares method:

$$
v=15.222-1.4081 T+0.0612 T^{2}-0.001 T^{3}, \mathrm{~mm}^{2} / \mathrm{s},
$$

where $T$ is the temperature of the mixture of diesters, $\mathrm{K}$.

These equations can be used in practical application of the mixture of diesters.

Fig. 6 shows the change in kinematic viscosity of the mixture of LDA diesters and 2-ethylhexan-1-ol with an increase in temperature. For comparison, the authors determined this physical characteristic for dibutyl adipinate and dibutyl phthalate as plasticizers, which exhibit similar properties.

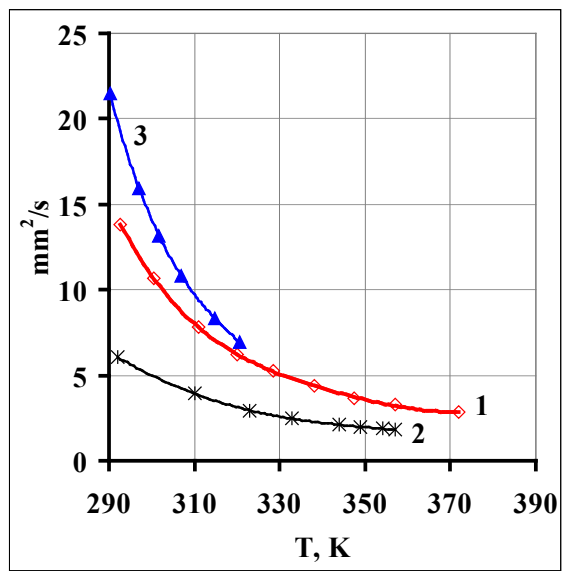

Fig. 6. Dependence of kinematic viscosity on temperature for: $1-$ mixture of LDA diesters and

2-ethylhexan-1-ol; 2 - dibutyl adipinate; 3 - dibutyl phthalate

Obviously, at the absolute value and the change in viscosity with an increase in temperature, the mixture of LDA diesters and 2-ethylhexan-1-ol is considerably closer to dibutyl phthalate than to dibutyl adipinate.

In general, physical parameters of the mixture of LDA diesters and 2-ethylhexan-1-ol correlate with indicators of dioctyladipinate. In particular, its density is $0.923-0.930 \mathrm{~g} / \mathrm{cm}^{3}$, AN ranges from 0.04 to $0.1 \mathrm{mg}$ of $\mathrm{KOH} / \mathrm{g}$ and kinematic viscosity is $13-17 \mathrm{~mm}^{2} / \mathrm{s}$ [5].

\section{Discussion of results of}

research into esterification by 2-ethylhexan-1-ol

Technological parameters of the process of LDA esterification by 2-ethylhexan-1-ol under different conditions are included in Table 1 . We selected minimal values of reaction time, chromaticity intensity of reaction products, $\mathrm{AN}$ of the reaction mixture and, accordingly, maximal value of conversion of carboxylic groups of LDA as optimality criteria.

It should be noted that the use of benzene as a component of the reaction mixture, which improves water removal, allows us to increase CG conversion from 95.8 to $99.5 \%$ (Table 1). The average and maximum temperatures of the reaction in the presence of benzene are also lower. Due to this, it is possible to decrease energy consumption in the esterification process.

Sulfuric acid is a less active catalyst of the process of LDA esterification by 2-ethylhexan-1-ol, since $89.4 \%$ conversion of $\mathrm{CG}$ is achieved in the presence of $\mathrm{H}_{2} \mathrm{SO}_{4}$ only within $180 \mathrm{~min}$ of the reaction, whereas in the presence of $p$ TSA, its value is $99.5 \%$ within $60 \mathrm{~min}$ of the reaction. A higher concentration of mineral acid is required to achieve the specified values of CG conversion.

The use of $p$ TSA as a catalyst provides the value of CG conversion of over $98 \%$ under condition of catalyst's concentration of $1.3 \cdot 10^{-2} \mathrm{~mol} / \mathrm{dm}^{3}$. A decrease in the content of the catalyst in the reaction mixture increases the reaction duration by half and provides for $95.3 \%$ CG conversion, the acid number of the reaction mixture is $9.1 \mathrm{mg} \mathrm{KOH} / \mathrm{g}$, which greatly increases LDA losses, which in such systems are found both as a small amount of unreacted acids, and mainly as monoesters [23].

The high value of chromaticity intensity of the reaction mixture $\left(3.0-4.7 \mathrm{mg}\right.$ of $\mathrm{I}_{2}$ per $\left.100 \mathrm{~cm}^{3}\right)$ indicates possible course of side reactions and contamination of reaction products with impurities, contained in catalysts. Application of activated carbon of different brands allows us in the process of esterification of lower dicarboxylic acids by 2-ethylhexan-1-ol to decrease chromaticity of the reaction products under conditions of preserving the value of CG conversion of $98.0-99.4 \%$. At the same time, the use of the amount of activated carbon DCL 200 that is more than optimal ( $0.3 \%$ by weight) inhibits the reaction and requires more reaction time to achieve high $\mathrm{CG}$ conversion.

Results of the performed research correlate with the known regularities of processes of esterification of dicarboxylic acids by aliphatic alcohols. At the same time, they complement and extend the base of experimental data on the technology of diester plasticizers in terms of using new raw material resources and conditions for carrying out a specific technological process. Almost complete conversion of carboxylic groups of reagents of $99.4-99.5 \%$, achieved within 60-70 minutes under conditions of catalysis by $p$-toluensulphonic acid, will provide for high specific performance for diesters even if the esterification process is performed under periodic conditions. The use of benzene as a component of the reaction mixture has advantages both in provision of almost complete LDA conversion and in a decrease in heat consumption for removal of water, formed in the process of esterification. 
Table 1

Technological parameters of the process of LDA esterification by 2-ethylhexan-1-ol. EH: LDA is 2.61:1 mol.

\begin{tabular}{|c|c|c|c|c|c|c|c|c|}
\hline Catalyst & $\begin{array}{c}\mathrm{C}(\mathrm{Cat}) \cdot 10^{2}, \\
\mathrm{~mol} / \mathrm{dm}^{3}\end{array}$ & $\begin{array}{c}\omega\left(\mathrm{C}_{6} \mathrm{H}_{6}\right), \% \\
\text { by weight }\end{array}$ & $\begin{array}{c}\text { Activated } \\
\text { carbon }\end{array}$ & $\begin{array}{c}\omega(\mathrm{AC}), \% \\
\text { by weight }\end{array}$ & Time, min & $\begin{array}{c}\text { AN, } \\
\mathrm{mg} \mathrm{KOH} / \mathrm{g}\end{array}$ & $\mathrm{C}(\mathrm{CG}), \%$ & $\begin{array}{c}\text { Iodine scale, } \\
\mathrm{mg} \mathrm{I}_{2} / 100 \mathrm{~cm}^{3}\end{array}$ \\
\hline$p \mathrm{TSA}$ & 1.4 & 0.0 & - & 0.0 & 60 & 9.7 & 95.8 & 3.4 \\
\hline$p \mathrm{TSA}$ & 1.3 & 15.2 & - & 0.0 & 60 & 1.1 & 99.5 & 3.0 \\
\hline $\mathrm{H}_{2} \mathrm{SO}_{4}$ & 2.6 & 15.4 & - & 0.0 & 180 & 3.2 & 98.4 & 4.7 \\
\hline$p \mathrm{TSA}$ & 0.7 & 15.1 & DCL 200 & 0.6 & 180 & 9.1 & 95.3 & 0.7 \\
\hline$p \mathrm{TSA}$ & 1.3 & 15.4 & DCL 200 & 0.6 & 170 & 3.9 & 98.0 & 1.1 \\
\hline$p \mathrm{TSA}$ & 1.3 & 15.6 & DCL 200 & 0.3 & 70 & 1.1 & 99.4 & 1.1 \\
\hline$p \mathrm{TSA}$ & 1.3 & 15.2 & BAU & 0.3 & 70 & 1.3 & 99.4 & 1.3 \\
\hline$p \mathrm{TSA}$ & 1.3 & 15.2 & $208 \mathrm{CP}$ & 0.3 & 65 & 1.5 & 99.2 & 1.1 \\
\hline
\end{tabular}

Results of research into esterification process with the use of activated carbon are also of practical importance. Such technique allows improving the quality of the mixture of diesters as finished product, because a decrease in chromaticity makes it possible to apply the products of LDA esterification by 2-ethylhexan-1-ol in manufacturing of colorless polymer products. Unfortunately, in the process of this research it was not possible to achieve almost complete decolorization of products of LDA esterification by 2-ethylhexan-1-ol.

This sets the task of subsequent improvement of the process in this respect. Practical solution of the problem of obtaining the mixture of diesters with minimal chromaticity includes the search for varieties of activated carbon with better adsorption properties and research in other catalysts of the process that contribute to minimal progress of side reactions in the process of esterification. In general, indicated diesters can compete with industrial plasticizers, such as dioctyladipinate and dibutyl phthalate.

\section{Conclusions}

1. We determined the influence of benzene, the type and concentration of a catalyst, the type and amount of activated carbon on technological parameters of the process of esterification of lower dicarboxylic acids by 2-ethylhexan-1-ol. It was shown that $p$-toluensulfonic acid is a more active catalyst for the reaction of esterification compared with sulfuric acid. It was established that existence of benzene in the reaction mixture provides for higher conversion of dicarboxylic acids and milder conditions of the process, and addition of activated carbon in the amount of $0.3 \%$ by weight to reagents decreases the chromaticity intensity of the reaction mixture by almost 3 times.

2 . It was found that optimal conditions of the process of esterification of lower dicarboxylic acids by 2-ethylhexan-1-ol is the concentration of the catalyst of $p$-toluensulfonic acid of $1.3 \cdot 10^{-2} \mathrm{~mol} / \mathrm{dm}^{3}$, mole ratio of LDA:EH of $2.65: 1$ and benzene content in the reaction mixture of $\sim 15 \%$ by weight and that of activated carbon of $0.3 \%$ by weight. Under these conditions, we achieved almost complete quantitative yield (over $99.5 \%$ ) of mixture of diesters of succinic, glutaric and adipic acids and of 2-ethylhexan-1-ol.

3. The composition and physical indicators of the mixture of diesters of succinic, glutaric and adipic acids, and 2-ethylhexan-1-ol, separated from the reaction products were determined. It was found that mixtures of diesters make up $0.923-0.930 \mathrm{~g} / \mathrm{cm}^{3}$, acid number ranges from 0.04 to $0.1 \mathrm{mg} \mathrm{KOH} / \mathrm{g}$, and kinematic viscosity is $13-17 \mathrm{~mm}^{2} / \mathrm{s}$.

\section{Acknowledgements}

The authors of this article express their acknowledgements for cooperation to Master of the Department of Technology of Organic Products at the National University "Lvivska Politechnika" Mr. Roman Lisnyi who participated in carrying out part of the experimental research.

\section{References}

1. FlexiSolv ${ }^{\circledR}$ solvent solutions - The Balanced Alternative [Electronic resource]. - Available at: http://flexisolv.com/en/index.html

2. Levanova, S. V. Sintez slozhnyh efirov iz zhidkih othodov proizvodstva kaprolaktama [Text] / S. V. Levanova, V. I. Gerasimenko, I. L. Gerasimenko et. al. // Rossiyskiy Himicheskiy Zhurnal. - 2006. - Vol. L, Issue 3. - P. 37-42.

3. Nafikova, R. F. Poluchenie ftalatnogo plastifikatora s ispol'zovaniem kubovyh ostatkov butilovyh spirtov [Text] / R. F. Nafikova, Zh. F. Rahmatullina, A. A. Rahimkulova et. al. // Bashk. him. zhurnal. - 2006. - Vol. 13, Issue 3. - P. 60-62.

4. Enyutina, M. V. Nekotorye aspekty reaktsii eterifikatsii spirtovyh othodov pishchevyh i neftekhimicheskih proizvodstv [Text] / M. V. Enyutina, Yu. M. Petyhin // Materialy 41 otchetnoy nauchnoy konferentsii za 2002 god. - Voronezh: Izd-vo VGTA, 2003. P. $207-208$.

5. DOA - dioktiladipinat [Electronic resource]. - Available at: http://rpch.ru/katalog/plastifikatory/doa-dioktiladipinat/

6. Altnau, G. G. Alternative Lösemittel: Mehr Mut zum Wechseln [Text] / G. G. Altnau // Git Sicherheit+Management. - 2000. Issue 2. - P. 178-179.

7. Otera, J. Esterification: Methods, Reactions, and Applications [Text] / J. Otera, J. Nishikido. - WILEY-VCH Verlag GmbH \& Co. KGaA, Weinheim, Second, Completely Revised, and Enlarged Edition, 2010. - 374 p. doi: 10.1002/9783527627622 
8. Baghernejad, B. Application of p-toluenesulfonic Acid (PTSA) in Organic Synthesis [Text] / B. Baghernejad // Current Organic Chemistry. - 2011. - Vol. 15, Issue 17. - P. 3091-3097. doi: 10.2174/138527211798357074

9. Sakakura, A. Open-air and solvent-free ester condensation catalyzed by sulfonic acids [Text] / A. Sakakura, Y. Koshikari, K. Ishihara // Tetrahedron Letters. - 2008. - Vol. 49, Issue 34. - P. 5017-5020. doi: 10.1016/j.tetlet.2008.06.058

10. Kriska, C. E. The efficacy of some catalysts used in synthesis of phthalates [Text] / C. E. Kriska, D. Modra // Annals of West University of Timisoara. Series of Chemistry. - 2012. - Vol. 21, Issue 2. - P. 47-56.

11. Ren, Y. M. A Simple Procedure for the Esterification and Transesterification Using p-Toluene Sulfonic Acid as Catalyst [Text] / Y. M. Ren, Z. C. Wu, R. C. Yang, T. X. Tao, J. J. Shao, Y. G. Gao et. al. // Advanced Materials Research. - 2013. - Vol. 781-784. P. 259-262. doi: 10.4028/www.scientific.net/amr.781-784.259

12. Wang, J. A study of esterification of caffeic acid with methanol using p-toluenesulfonic acid as a catalyst [Text] / J. Wang, S. Gu, N. Pang, F. Wang, F. Wu // Journal of the Serbian Chemical Society. - 2013. - Vol. 78, Issue 7. - P. 1023-1034. doi: 10.2298/ jsc120802101w

13. Melnyk, S. R. Oderzhannia sumishei alkiltsykloheksyladypinativ spyrtiv S4-S5 [Text] / S. R. Melnyk, I. Ye. Nykulyshyn, M. I. Solod // Visnyk Skhidnoukrainskoho Natsionalnoho universytetu im. Volodymyra Dalia. - 2015. - Issue 7 (224). - S. 19-24.

14. Pacheco, B. S. Eco-friendly synthesis of esters under ultrasound withp-toluenesulfonic acid as catalyst [Text] / B. S. Pacheco, C. F. P. Nunes, C. T. Rockembach, P. Bertelli, M. F. Mesko, M. Roesch-Ely et. al. // Green Chemistry Letters and Reviews. - 2014. Vol. 7, Issue 3. - P. 265-270. doi: 10.1080/17518253.2014.941950

15. Barshteyn, R. S. Plastifikatory dlya polimerov [Text] / R. S. Barshteyn, V. I. Kirilovich, Yu. E. Nosovskiy. - Moscow: Himiya, 1982. $-200 \mathrm{p}$.

16. Melnyk, S. R. Syntez diesteriv na osnovi spyrtiv S4-S5 [Text] / S. R. Melnyk, Yu. R. Melnyk, N. Ya. Kachmar, V. V. Reutskyi // Visnyk Natsionalnoho universytetu „Lvivska politekhnika”. - 2005. - Issue 529. - P. 128-130.

17. Ekofil'tr-Sorbosgrup. Aktivirovannyy ugol' Chemviron Carbon [Electronic resource]. - Available at: http://activcarbon.com.ua/ category/21.html

18. Methodology for Lipids. Estimation of free fatty acids [Electronic resource]. - Available at: http://www.biocyclopedia.com/index/ plant_protocols/lipids/Estimation_of_free_fatty_acids.php

19. Technical Data Sheet Eastman ${ }^{\mathrm{TM}}$ 2-Ethylhexanol [Electronic resource]. - Available at: http://ws.eastman.com/ProductCatalogApps/ PageControllers/ProdDatasheet_PC.aspx?product=71000124

20. Ekofil'tr-Sorbosgrup. Aktivirovannyy ugol' 208CP [Electronic resource]. - Available at: http://activcarbon.com.ua/ product/32.html

21. SORBIS GROUP. Sorbenty tol'ko vysshego kachestva. Ugol' aktivirovannyy (BAU-A) [Electronic resource]. - Available at: http://sorbis-group.com/products/ugol-aktivirovan/ugol-aktivirovan-bau-a.php

22. Melnyk, S. Selectivity of Formation and Yield of Dicarboxylic Acid Mono- and Diesters under Stationary Conditions [Text] / S. Melnyk, B. Dzinyak // Chemistry \& Chemical Technology. - 2015. - Vol. 9, Issue 3. - P. 325-332. doi: 10.23939/chcht09.03.325 